\title{
Access to Public Transit and Its Influence on Ridership for Older Adults in Two U.S. Cities
}

\author{
Daniel Baldwin Hess \\ University at Buffalo, State University of New York ${ }^{a}$
}

\begin{abstract}
Growth in the population of older adults (age 60 and above) in coming years will challenge urban planners and transportation managers to provide travel options that support autonomy. To investigate barriers that older adults experience in using public transit, this research explores associations between older adults who do and do not ride fixed-route public transit and their neighborhood walking access to buses and trains. The research tests whether or not the distance between a trip origin or destination and a transit stop or station is a significant factor in predicting frequency of transit ridership. Data from a survey of older adults in California and New York is used to regress older adults' frequency of riding public transit against explanatory variables, including demographic and socioeconomic variables, access and mobility measures, and neighborhood characteristics. Findings suggest that self-reported walking distance to transit has a statistically significant influence-in San José, California, but not in Buffalo, New York-in predicting transit ridership frequency. Drivers are more sensitive to walking distance than nondrivers. Models estimate that in San José, each additional five minutes in perceived walking time to transit decreases transit ridership frequency by five percent for nondrivers and by 25 percent for drivers. Older adults are likely to ride transit more often if they are male, nonwhite, and low income.
\end{abstract}

Keywords: Older adults; Elderly; Senior citizens; Public transit; Access; Walking; Physical activity

\section{Introduction}

When older adults (age 60 and above) have inadequate access to transportation, they tend to experience lower levels of physical activity, reduced independence, and greater health risks. In coming years, a noteworthy challenge for planners and policymakers will be to expand mobility on and access to public transit for the growing population of older adults in the United States.

Although the private automobile remains the primary travel mode for a majority of older adults, capturing 90 percent of travel (Federal Highway Administration 2001), public transit can provide autonomous travel for those who cannot drive or choose not to drive. Various studies conducted since the mid-1990s by the Surface Transportation Policy Project (STPP), the American Association of Retired Persons (AARP), the American Public Transportation Association (APTA), and other policy organizations and researchers have arrived at the same conclusion: the United States is ill-prepared to provide adequate transportation for the rapidly growing number of older adults (Millar 2005).

adbhess@buffalo.edu 
Conventional wisdom suggests that if older adults do not drive, or are not driven by others, they will use other modes of transportation-riding transit and walking - more frequently. However, use of alternatives to driving has declined in recent years among older adults (Collia et al. 2003; Wallace and Franc 1999). The most frequent mode of travel for older adults is driving or being driven, followed by walking; riding public transit is the third most frequent choice (Rosenbloom and Waldorf 2001). Consequently, less than two percent of daily intracity travel by older adults in the United States occurs on public transit (Burkhardt 2003; Burkhardt et al. 2002; Collia et al. 2003). It is a worthwhile pursuit, then, to identify barriers that older adults face in using fixed-route public transit as the population of older adults in the United States is projected to reach approximately 70 million by 2030 (U.S. Bureau of Census 1996). Transit agencies that have taken action to tailor their service in recent years to meet the needs of older adults and riders with disabilities have, indeed, experienced ridership increases (Hess et al. 2002; Rosenbloom and Fielding 1998)

This study takes as its central premise the assertion that there are great accessibility and mobility gains to be realized for older adults—and, indeed, for riders and potential riders of all ages-by identifying barriers to riding fixed-route public transit. Introducing interventions in public transit systems that remove or reduce those barriers can make transit riding more convenient for older adults. Public transit systems are already established in U.S. metropolitan areas and already receive public subsidies, making public transit a better choice for serving older adults than privately funded dedicated van services, which are expensive to establish and operate and may not comply with the requirements of the Americans with Disabilities Act (ADA).

To investigate potential barriers, this research explores the relationship between older adults (both those who do and do not ride fixed-route public transit) ${ }^{1}$ and their neighborhood walking access to buses and trains. The hypothesis is that for older adults age 60 and above, the distance between an origin or destination and a transit stop or station is a significant factor in predicting ridership (Neilson and Fowler 1972). Various other characteristics that influence the decision to ride transit-including physical capacity, housing type and living arrangements, and income-are used in the analysis as well.

This article employs data from a survey of older adults in California and New York to determine how frequently older adults ride public transit. Given that access to public transit by foot is a critical component of a trip, a particular focus of inquiry in this article is proximity as a predictor of ridership frequency. The remainder of this article is structured as follows: relevant literature is reviewed to help develop a framework for conceptualizing the relationship between transit ridership and various explanatory variables, including proximity to transit stations; original survey data is introduced, and survey responses are combined with environmental data from other sources; the theoretical model is then implemented by undertaking regression analysis; observations and recommendations are presented at the conclusion.

${ }^{1}$ Many older adults with certified disabilities rely on paratransit service (also called demand response). The demand for paratransit service increasingly exceeds both the budget and capacity of most transit operators (Millar 2005). Researchers predict that the gap between the supply and demand of paratransit service will continue to widen. 


\section{Background}

Within scholarly literature in the areas of transportation planning, policy, and design-especially research that seeks to improve and increase access to transportation-limited attention has been focused exclusively on older adults (Cunningham and Michael 2004; Frank and Engelke 2001; Frank et al. 2003; Ory et al. 2003; Rosenbloom 2003; Wallace and Franc 1999). This is likely because most published works about travel behavior focus on travel (and especially commuting) for working-age adults. However, researchers who investigate access and mobility for older adults (Bailey 2004; Burkhardt et al. 2002; Millar 2005; O'Gara 2002; Rosenbloom 2003) noted that older adults experience poorer quality of life when that access is limited (Peel et al. 2002).

In addition, public health researchers have in recent years turned to evaluating the built environment in order to quantify the influence of various characteristics on physical activity (Frank and Engelke 2001; Handy et al. 2002). The known health benefits for older adults of physical activity (Rowe and Kahn 1998; Singh 2002) suggest that age-sensitive urban design and public policy can promote active living (Humpel et al. 2002; Owen et al. 2004).

\subsection{Access}

The decision to ride public transit is based on a complex set of abilities and circumstances, including personal mobility, availability of alternatives, cost of service, safety in getting from origin to stop and stop to destination (Hess et al. 2004), travel barriers along pedestrian paths, and other factors.

Older adults who are able to travel on their own can manage their access and mobility in their communities with a certain level of independence; however, those who depend on others for rides experience a significant loss of mobility (Straight 1997). Older adults hampered by mobility limitations often see the easily accessible areas for activities like shopping and socializing shrink to a "footprint" that may be as small as 2.6 square $\mathrm{km}$ (one square mile) surrounding their homes (O'Gara 2002). This is especially true for the increasing number of older adults who live alone and do not have a spouse or other family member to act as driver. ${ }^{2}$ In fact, a person may travel more frequently if they live with another person upon whom they can rely for travel assistance. Nevertheless, older adults choose walking for a greater share of daily travel than their younger counterparts (Collia et al. 2003).

A short, comfortable walk from an origin or destination to a transit station or bus stop is a rule of thumb for multimodal urban planning. Urban planners typically assume that people of all ages will comfortably walk approximately 400 meters (one-quarter mile) to reach transit stops or stations (Southworth and Ben-Joseph 2003; Untermann 1984); as walking distance to public transit increases, people are less likely to use it if they have other travel alternatives (Zhao et al. 2003). Convenient access to public transit is a foundation for neighborhood planning for

${ }^{2}$ Older women are three times more likely to live alone than men (Wallace and Franc 1999). Additionally, they may be frail and may survive on limited incomes. Consequently, safe mobility for older women living alone is a key concern for planners (Burkhardt et al. 2002). As people live longer, the gap between driving expectancy (the age at which a person stops driving) and life expectancy increases (Dollemore 2002). This gap is almost twice as wide for women as it is for men. Women rely on rides from others, public transit, and walking-in other words, transportation modes other than driving themselves-for roughly ten years; the period of dependency for men is approximately six years (Dollemore 2002). 
pedestrians and transit-oriented design, and (to a lesser extent) for neotraditional neighborhood design and New Urbanism.

Riding transit requires a passenger to possess sufficient mobility for travel—by walking some or all of the way-between origins, destinations, and transit stops. The presence of sidewalks and pedestrian pathways increases the potential number of trips (Kitamura et al. 1997) and the likelihood of walking (Corti et al. 1996; Hess et al. 1997, 1999; Parsons Brinckerhoff Quade and Douglas 1993). The quality of a pedestrian environment is a strong predictor of walking behavior and travel (Cervero and Kockelman 1997), and the presence of sidewalks on the shortest route to a destination tends to increase the likelihood of travel on foot (Rodriguez and Joonwon 2003). Conversely, difficult walking conditions reduce the likelihood of walking in lieu of driving (Loukopoulos and Gärling 2005). In various studies of walking behavior and commercial districts (Handy 1996a,b; Handy and Clifton 2001; Handy et al. 1998; King et al. 2003; Patterson and Chapman 2004), neighborhood design characteristics-including high traffic volumes on streets (Wilcox et al. 2003) and the safety of streets and sidewalks (Booth et al. 2000)—influence the decision to walk for neighborhood errands. ${ }^{3}$

Consequently, people are more active in neighborhoods with higher population density, mixed residential and commercial land uses, street connectivity, and multimodal accessibility (Handy et al. 2002; Saelens et al. 2003). Higher residential densities have been shown to decrease automobile mode share (Schimek 1996), and greater pedestrian access increases public transit mode share and decreases solo driving (Hsiao et al. 1997).

Personal mobility is requisite for walking access to public transit. A 1999 study conducted in Baltimore determined that older adults' ability to walk three blocks is the strongest predictor of travel frequency (Ketron, Division of the Bionetics Corporation 1999). ${ }^{4}$ Pedestrian infrastructure located along a travel route from home to a transit station may lessen the burden of walking for older adults (Burkhardt 2003; Straight 1997). Desirable pedestrian infrastructure includes sidewalks, curb ramps, street lighting, street crossings, and resting places. ${ }^{5}$ Older adults can be inconvenienced and discomfited by having to wait for bus service without shelter from inclement weather (Cozens et al. 2004; Patterson 1985). Comfort is critical for older adult transit passengers, as trips on public transit are estimated to take more than twice as much time on average than automobile trips between the same origin and destination (Rosenbloom and Morris 1998).

Older pedestrians may encounter additional challenges while navigating urban streetscapes: steep grades, high curbs, excessive numbers of stairs, and dangerous entrances onto busy roadways to cross streets or board buses (Iwarsson and Ståhl 1999). Often, the challenge of navigating an urban streetscape is magnified by diminished vision, hearing, or other sensory loss

\footnotetext{
${ }^{3}$ Similarly, research on design guidelines for greenways shows that the presence of more compelling destinations encourages people to walk further (Lusk 2002). A study in Pennsylvania showed that women who live near trails, parks, and neighborhood services walk more than women who do not (King et al. 2003).

${ }^{4}$ In focus groups of 42 nationwide transportation systems, 100 percent of managers respond that shorter walking distances from home to bus stops are identified as positive service attributes of an ideal transit system (Burkhardt et al. 2002).

5 Findings from a nationwide telephone survey conducted by International Communications Research in cooperation with the American Association of Retired Persons-with 710 respondents age 75 years and older-highlights the potential effectiveness of pedestrian infrastructure (Straight 1997); the study concludes that 50 percent of nondriver respondents cannot walk to a bus stop if they want to, yet 32 percent report that the trip may be possible if they have access to a resting place (such as a bench) along the way.
} 
associated with the natural aging process (Walter et al. 2004). A lack of pedestrian-friendly zones within automobile-dominated cityscapes can present insurmountable physical obstacles for older adults (Iwarsson and Ståhl 1999). In addition, many older adults simply live too far from existing transit routes to have reasonable access (Rosenbloom 2003).

\subsection{Travel Patterns and Destinations}

Previous research has investigated the degree to which urban density (population or households per unit of land area) influences travel mode decisions. Various studies have found that lower densities increase auto ownership, auto mode choice for trips, and per capita distance traveled (Beesley and Kain 1964; Cheslow and Neels 1980; Holtzclaw et al. 2002; Kitamura et al. 2001). In addition, mixed residential and commercial land uses can encourage lower rates of automobile ownership (Hess and Ong 2002), and traditional built-environment features (street network, building type, land use mix) can reduce non-work travel (but not necessarily overall travel) (Cervero and Kockelman 1997). Higher densities, in which there is less spatial separation of origins and destinations and more travelers, support public transit more than lower densities do.

Transit service is often oriented toward commuters traveling to and from homes and offices during peak travel hours. Unfortunately, travel conditions during these hours-including congestion, fast-moving traffic, and crowded buses—are the very conditions that older adults may seek to avoid. The greatest share of transit ridership by older adults takes place in areas of concentrated population with efficient urban infrastructure (Evans 2001, 1999).

Many older adults who use public transit prefer to avoid travel during peak commuting hours and at night (Banister and Bowling 2003). Based on interviews with 1,000 subjects, a study in the United Kingdom predictably found that older adults are more active outside the home during daylight hours than after dark (Alsnih and Hensher 2003). As a result, they perform much of their travel during the midday and on weekends (Collia et al. 2003). During these off-peak times, fixed-route transit service tends to be less frequent than it is during weekday peak hours (Glasgow and Blakeley 2000; Hayden et al. 2004; Nelson 2002; Taylor et al. 2000).

\section{Research Method}

\subsection{Description of Study Areas}

This study focuses on Buffalo, situated in western New York State along the eastern shores of Lake Erie, and on San José, California, located in the Silicon Valley south of the San Francisco Bay region. Both are medium-sized metropolitan regions, but they provide several juxtapositions for comparative study. Buffalo is a former industrial region in the Northeast Rust Belt, while San José is a growing city with a technology-based economy located on the West Coast.

The population of Buffalo, the second largest city in New York State, is 292,600, and 13.5 percent of residents are age 65 or older (U.S. Bureau of Census 2000). Buffalo is the tenth "oldest" region among U.S. metropolitan areas with 500,000 or more residents (Tan 2006). ${ }^{6}$ The city of San José is nearly three times as large as Buffalo, with a population of almost 900,000.

\footnotetext{
${ }^{6}$ In addition, Buffalo ranks fifth among U.S. metropolitan areas that have experienced the greatest declines in the number of residents age 35 and under (Frey 2003).
} 
With older adults comprising only 10 percent of the city's population, San José is a "younger" city than Buffalo. The average population density of Buffalo is 38 percent higher than that of San José.

Evidence of a difference in urban form between Buffalo and San José can be found in the evolution of housing development (see Table 1). San José has nearly twice as many housing units as Buffalo, and the proportion of single-unit-detached housing units in San José is nearly twice that of Buffalo. The age of housing suggests urban structure, as U.S. housing throughout the twentieth century generally was built on increasingly larger lot sizes in neighborhoods with greater accommodation (in public rights-of-way and on private property) for automobiles. That is, earlier decades were characterized by pre-automobile development and higher densities, while later development is characterized by a number of features that reduce walkability—including lower development densities, large lot sizes, wider streets, off-street parking, garages, and driveways. Table 1 also shows that 86 percent of all housing units in Buffalo were built prior to 1960, while in San José only 21 percent of all housing units were built prior to 1960. Growth in Buffalo peaked in the 1950s (Hess 2005a), but San José has a greater percentage of housing units built in recent decades, reflecting the city's growth throughout the 1970s, 1980s, and 1990s. Buffalo possesses new, lower-density residential environments similar to

Table 1: Age and Type of Housing Units

\begin{tabular}{lrr}
\hline & Buffalo, NY & San José, CA \\
\hline Total housing units & 14,5574 & 28,1706 \\
Share single-unit, detached & $30 \%$ & $58 \%$ \\
Year structure built & & \\
1990 or later & $2 \%$ & $12 \%$ \\
1980 to 1989 & $2 \%$ & $15 \%$ \\
1970 to 1979 & $4 \%$ & $28 \%$ \\
1960 to 1969 & $6 \%$ & $24 \%$ \\
1940 to 1959 & $28 \%$ & $16 \%$ \\
1939 or earlier & $58 \%$ & $5 \%$ \\
\hline
\end{tabular}

Source: 2000 U.S. Census, Summary File 3

those found in San José, but in Buffalo they are located in suburban municipalities (outside the study area for this research), while in San José they are located within the boundaries of the region's central city.

Table 2 summarizes sociodemographic characteristics of the two study sites. Older adults in Buffalo constitute a greater share of the population than they do in San José. Buffalo has higher shares of older adults in poverty, and San José has higher shares of older adults with disabilities. San José has a smaller share of white older adults than Buffalo; in Buffalo, African Americans constitute the largest racial group of older adults after whites, and in San José, Asian/Pacific Islanders constitute the largest racial group of older adults after whites. The share of older adult

\footnotetext{
${ }^{7}$ Buffalo's 2000 population (292,600) is spread over 106 sq. km (41 sq. mi.) yielding a population density of 2,760 per sq. km. (7,200 per sq. mi.). San Josés 2000 population $(893,900)$ is spread over 453 sq. km (175 sq. mi.) yielding a population density of 1,973 per sq. $\mathrm{km}$ (5,200 per sq. mi.).
} 
householders without access to vehicles is more than twice as high in Buffalo as it is in San José. Between 1990 and 2000, the share of older adults decreased faster than the population loss rate in Buffalo, and the share of older adults increased faster than the population growth rate in San José.

Table 2: Sociodemographic Profiles of Older Adults in Study Areas

\begin{tabular}{|c|c|c|}
\hline & Buffalo, NY & San José, CA \\
\hline All Persons & 292,648 & 893,889 \\
\hline 1990-2000 change & $-11 \%$ & $14 \%$ \\
\hline With disability & $43 \%$ & $30 \%$ \\
\hline Below poverty & $26 \%$ & $9 \%$ \\
\hline Older Adults (age 65+) & 39,524 & 72,625 \\
\hline 1990-2000 change & $-19 \%$ & $29 \%$ \\
\hline With disability & $48 \%$ & $86 \%$ \\
\hline Below poverty & $13 \%$ & $6 \%$ \\
\hline Share of population & $13.5 \%$ & $8.1 \%$ \\
\hline \multicolumn{3}{|c|}{ Age Distribution of Older Adults } \\
\hline Younger $(65-74)$ & $51 \%$ & $57 \%$ \\
\hline Older $(75-84)$ & $37 \%$ & $32 \%$ \\
\hline Oldest ( 85 and above) & $12 \%$ & $11 \%$ \\
\hline \multicolumn{3}{|l|}{ Race of Older Adults } \\
\hline White & $70 \%$ & $63 \%$ \\
\hline African American & $28 \%$ & $2 \%$ \\
\hline Asian/Pacific Islander & $<1 \%$ & $26 \%$ \\
\hline Other & $<1 \%$ & $9 \%$ \\
\hline \multicolumn{3}{|l|}{ Ethnicity of Older Adults } \\
\hline Hispanic/Latino & $2 \%$ & $16 \%$ \\
\hline Older Adult Households & 27,159 & 38,638 \\
\hline Share of all households & $22 \%$ & $14 \%$ \\
\hline Zero vehicles & $38 \%$ & $17 \%$ \\
\hline One or more vehicle & $62 \%$ & $83 \%$ \\
\hline
\end{tabular}

Source: 1990 and 2000 U.S. Census, Summary files 1 and 3.

Throughout Erie County (Buffalo), traditional fixed-route transit service is provided by the Niagara Frontier Transportation Authority (NFTA), which operates a 9.7-kilometer light rail route, 55 fixed bus routes, and a paratransit service. The Santa Clara Valley Transportation Authority (San José) operates 68 kilometers of light rail on three routes, 82 bus routes, and a paratransit service. 


\subsection{Data and Analysis}

This study uses data from a survey of older adults conducted in Buffalo, New York, and San José, California in late 2005 and early 2006. The purpose of the survey was to collect information about barriers-perceived and objective-older adults encounter when using public transit.

A single-stage simple random name and address list of adults age 60 or over was generated from the client databases of the Erie County Department of Senior Services and the Office on Aging for the city of San José. In Buffalo, 400 questionnaires were mailed and 171 completed surveys were returned, a response rate of 43 percent; in San José, 900 surveys were mailed and 286 were returned, a response rate of 32 percent. The client databases of the agencies in Buffalo and San José include names and addresses of individuals who have at some point used an agency service-this could include persons with infrequent contact, such as those who have registered to receive a senior discount card, or frequent contact, such as participating in services or meal programs at senior centers. Although demographic data for agency clients is unavailable, it is likely that clients of senior services organizations have lower incomes than older adults not registered with such organizations. The survey was confidential and anonymous; names and street addresses were not recorded. ${ }^{8}$

Table 3 provides demographic profiles of survey respondents in the two study sites. The mean ages are 76 and 77 years and the age distribution shows greater shares in San José in the two older categories than in Buffalo. The racial distribution of survey respondents in Buffalo includes a smaller share of African Americans and a larger share of whites than the racial distribution reported in the U.S. Census, while the racial distribution of respondents in San José includes fewer whites and more Asian/Pacific Islanders than the racial distribution in the U.S. Census. Although the U.S. Census reports higher poverty rates in Buffalo than in San José, there is a greater share of respondents in San José with an average household monthly income less than \$1,000 than in Buffalo. A greater share of respondents in Buffalo than in San José live alone, perhaps reflecting higher housing costs in California than in upstate New York. The housing arrangements of older adults are important because a challenge in coming years will be to provide travel options to the large number of older adults who live in single-family detached homes (Coughlin and Lacombe 1997) in low-density, sprawling areas (Frey 2003; Rosenbloom 2003) that are typically poorly served by public transit. The share of respondents with drivers licenses is greater in Buffalo than in San José. Similar shares of respondents in the two cities report that they use assistive devices (such as canes, walkers, wheelchairs, or power scooters) and approximately 70 to 80 percent can walk to a nearby bus stop.

Not included in the table is survey respondents' assessment of the difficulty they experience in getting to public transit due to hot or cold weather (Peck 2009). About 35 percent of the pooled respondents stay home because of the temperature (always 4.2 percent, sometimes 31.1 percent); about 27.5 percent have difficulty getting to transit when it is too hot and 36.5 percent have difficulty when it is too cold. In general, the largest weather barriers to public transit appear to be snow or ice and rain. In Erie County, snow is a barrier for 60.3 percent of respondents

${ }^{8}$ The survey research methodology was approved by the Social and Behavioral Sciences Institutional Review Board at the University at Buffalo and by the Institutional Review Board at San José State University. A cover letter described the study and assured confidentiality and anonymity, and a mail-back postcard was used to request a questionnaire. A completed and returned survey indicated informed consent. The first mailing was preceded by a postcard that announced the study, and a reminder postcard was sent to nonresponders to encourage completion of the survey. 
Table 3: Demographic Profiles of Study Respondents

\begin{tabular}{|c|c|c|}
\hline Characteristic & Buffalo, NY & San José, CA \\
\hline Observations & 175 & 286 \\
\hline \multicolumn{3}{|l|}{ Demographic Characteristics } \\
\hline Age range & $60-96$ & $60-97$ \\
\hline Mean age & 76 & 77 \\
\hline Age distribution & $\begin{array}{l}60-69: 16 \% \\
70-79: 54 \% \\
80+: 30 \%\end{array}$ & $\begin{array}{l}60-69: 12 \% \\
70-79: 51 \% \\
80+: 37 \%\end{array}$ \\
\hline Race and Ethnicity & $\begin{array}{l}93 \% \text { white } \\
7 \% \text { African American } \\
<1 \% \text { other }\end{array}$ & $\begin{array}{l}\text { 31\% white } \\
\text { 3\% African American } \\
50 \% \text { Asian } \\
13 \% \text { Latino/a } \\
\text { 3\% other }\end{array}$ \\
\hline Sex & $\begin{array}{l}67 \% \text { female } \\
33 \% \text { male }\end{array}$ & $\begin{array}{l}59 \% \text { female } \\
41 \% \text { male }\end{array}$ \\
\hline $\begin{array}{l}\text { Average Household Monthly } \\
\text { Income }\end{array}$ & $\begin{array}{l}23 \%<\$ 1,000 \\
77 \%>\$ 1,000\end{array}$ & $\begin{array}{l}41 \%<\$ 1,000 \\
59 \%>\$ 1,000\end{array}$ \\
\hline \multicolumn{3}{|c|}{ Access and Mobility Characteristics } \\
\hline Living Arrangements & $\begin{array}{l}51 \% \text { live alone } \\
49 \% \text { live with others }\end{array}$ & $\begin{array}{l}31 \% \text { live alone } \\
69 \% \text { live with others }\end{array}$ \\
\hline Driving & $\begin{array}{l}81 \% \text { have driver's license } \\
19 \% \text { lack driver's license } \\
\text { 37\% previously licensed } \\
63 \% \text { never licensed }\end{array}$ & $\begin{array}{l}\text { 59\% have driver's license } \\
41 \% \text { lack driver's license } \\
\text { 35\% previously licensed } \\
65 \% \text { never licensed }\end{array}$ \\
\hline Use of Assistive Device ${ }^{a}$ & $\begin{array}{l}9 \% \text { rely upon } \\
19 \% \text { do not use }\end{array}$ & $\begin{array}{l}15 \% \text { rely upon } \\
85 \% \text { do not use }\end{array}$ \\
\hline Access & $\begin{array}{l}55 \% \text { do not leave house more } \\
\text { than } 5 \text { times per week }\end{array}$ & $\begin{array}{l}54 \% \text { do not leave house more } \\
\text { than } 5 \text { times per week }\end{array}$ \\
\hline Transit Access & $\begin{array}{l}71 \% \text { can walk to transit stop } \\
29 \% \text { walking to transit stop is } \\
\text { very difficult or impossible }\end{array}$ & $\begin{array}{l}80 \% \text { can walk to transit stop } \\
20 \% \text { walking to transit stop is } \\
\text { very difficult or impossible }\end{array}$ \\
\hline
\end{tabular}

a "Assistive device" refers to cane, walker, wheelchair, or power scooter.

(always 15.7 percent, sometimes 44.6 percent). In San José, rain is a barrier for 55.6 percent of respondents (always 11.9 percent, sometimes 43.7 percent), and darkness is a barrier for 53.1 percent of respondents (always 13.6 percent, sometimes 39.5 percent). ${ }^{9}$

\footnotetext{
9 A mean score for weather variables is created by assigning each response a numeric value as follows: never ' 0 ,' rarely ' 1 ,' sometimes '2, and always ' 3 .' The mean score for each respondent could range from 0 to 3; a score of 0 represents no weather barriers to public transit, and a score of 3 represents pervasive weather barriers. Results show that there is no statistically significant $(p=.09)$ difference in the means between the two study sites (Peck 2009).
} 


\subsection{Walking to the Bus}

Research about walking is scant because data about walking behavior are not collected often (Transportation Research Record and Institute of Medicine 2005) and most researchers estimate walking access in the absence of robust data about revealed pedestrian behavior. However, the survey asked respondents in Buffalo and San José to report their transit ridership behavior and the distance from their home to the nearest bus or rail stop. Findings suggest that Buffalo has a greater share of respondents than San José who are non-transit riders, and San José has a greater share of respondents than Buffalo who are frequent or infrequent transit riders (see Table 4).

Table 4: Transit Ridership Frequency and Proximity

\begin{tabular}{lll}
\hline Characteristic & Buffalo, NY & San José, CA \\
\hline Transit Ridership & & \\
Frequent transit riders & $25 \%$ & $36 \%$ \\
Infrequent transit riders & $35 \%$ & $30 \%$ \\
Non-transit riders & $40 \%$ & $34 \%$ \\
Perceived Walking Time to Transit in Minutes, Mean (Range) & \\
Frequent transit riders & $8.3(2-30)$ & $10.6(0-45)$ \\
Infrequent transit riders & $7.7(2-45)$ & $12.5(2-60)$ \\
Non-transit riders & $8.0(1-40)$ & $12.4(0-80)$ \\
\hline
\end{tabular}

Note: In the last year, frequent transit riders rode one time or more per month, infrequent transit riders rode one time or more per year but less than one time per month, and non-riders did not ride transit.

In Buffalo, the perceived walking time to transit is 8.3 minutes for frequent transit riders, 7.7 minutes for infrequent transit riders, and 8.0 minutes for non-transit riders. In San José, the perceived walking times to transit for infrequent transit riders and for non-transit riders are similar (about 12.5 minutes) and are greater than the perceived time reported by frequent transit riders (10.6 minutes). In general, perceived walking time to transit in San José is about 30 to 55 percent greater than perceived walking time to transit in Buffalo. ${ }^{10} \mathrm{~A}$ two-sample $t$-test for the difference of means assuming unequal variance suggests that in Buffalo, the difference in proximity to transit for those who ride transit frequently and never is statistically significant at the 0.90 level, and in San José, the difference in proximity to transit for those who ride transit frequently and never (and also frequently and infrequently) is statistically significant at the 0.90 level.

Multivariate regression analysis makes it possible to investigate the association between perceived walking distance and the decision to ride transit or transit riding frequency. ${ }^{11}$ In the

${ }^{10}$ Previous research identified two likely explanations for the observation that perceived walking time lengthens as ridership frequency decreases: (a) actual proximity decreases as distance between home and transit stops for nonriders (presumed to reside in less-dense and more single-use urban environments) increases; and (b) to a lesser degree, those who do not walk tend to overestimate walking distances. This is not surprising, as people tend to misestimate distances around their homes (Golledge and Stimson 1997; Lloyd 1997).

${ }^{11}$ To specify an appropriate model to test relationships between the key variables of interest, a scattergram is used to plot the values of the dependent variable (transit ridership frequency) as a function of the independent variable (perceived distance to nearest station). As walking distance to transit increases, ridership frequency decreases. A 
linear multivariate relationship, the dependent variable $R$ (representing the annual number of rides on public transit $)^{12}$ is a function of four vectors of independent variables. The four integrated vectors include a vector of personal characteristics and self-capacity measures, a vector of variables that describe access and mobility, a vector of perceived barriers to riding transit, and a vector of variables that describe neighborhood characteristics. Thus, the model estimates the importance of demographic and socioeconomic characteristics, access and mobility, perception of ease of access, and neighborhood characteristics in transit ridership frequency.

Estimation of transit ridership frequency is assumed to be dependent on the ability to drive. The model includes an independent variable drive, a dichotomous variable indicating whether or not the respondent possesses a driver's license and has driven a car in the last month. This overcomes a frequent problem with self-reported driving behavior data in surveys of older adults: survey respondents who possess driver's licenses generally do not classify themselves as nondrivers, even if they have not driven a vehicle for a long time. A second set of models is created using binary logistic regression in which the dependent variable is a dichotomous variable indicating whether or not the respondent has taken a transit ride at least once in the previous year and the same independent variables as the linear regression. Table 5 provides a list of two dependent variables and 18 independent variables in four vectors, along with operational definitions and data sources.

Table 5: Variable Definitions

Variable

(Data Source)

\section{Dependent Variables}

transitridefreq (survey)

transitride (survey)

\section{Independent Variables \\ buffalosanjosé dummy (survey)}

\section{Personal Characteristics and Capacity}

age (survey)

sex (survey) able

\section{Operational Definition}

Number of times in last 12 months respondent has traveled (roundtrip) on public transportation expressed as continuous vari-

Dichotomous variable; $0=$ respondent did not ride transit in previous 12 months: 1 = respondent rode transit one or more times in previous 12 months

Dichotomous variable; 0 = survey respondent in Buffalo, $1=$ survey respondent in San José

Age of respondent expressed as continuous variable

Sex of respondent expressed as dichotomous variable: $0=$ male, $1=$ female

Continued on next page

variable transformation for walking distance is contemplated but not undertaken, since the relationship between walking distance and transit ridership is pronouncedly linear.

${ }^{12}$ Survey respondents were asked to report the average number of times per week they rode transit during the previous month. A "ride" on public transit refers to roundtrip travel. Responses are used to calculate an average monthly ridership, which is multiplied by 12 to yield an average annual ridership. 


\section{Variable}

(Data Source)

race (survey)

income (survey)

cane (survey)

wheelchair (survey)

\section{Perceived Barriers}

knowledge (survey)

transfer (survey)

physicalbarriers (survey)

compositeperception (survey)

\section{Access and Mobility \\ drive (survey)}

leavehouse (survey)

livealone (survey)

housetype (survey)

\section{Operational Definition}

Race of respondent expressed as dichotomous variable: $0=$ white or Caucasian, $1=$ all other races

Average monthly household income of respondent expressed as categorical variable: $0=\$ 500$ or less, $1=\$ 501$ to $\$ 1,000,2=\$ 1,001$ to $\$ 2,000,3=\$ 2,001$ to $\$ 4,000,4=\$ 4,001$ or more

Categorical variable describing how frequently responded uses a cane: $0=$ never, $1=$ rarely, $2=$ sometimes, $3=$ always

Categorical variable describing how frequently responded uses a wheelchair: $0=$ never, $1=$ rarely, $2=$ sometimes, $3=$ always

Categorical response to the statement "I am concerned that I will not know where I am going on the bus, light rail, or subway": $0=$ strongly disagree, 1 = disagree, 2 = agree, 3 = strongly agree

Categorical response to the statement "I am less likely to ride public transit if $\mathrm{I}$ have to transfer to a second bus or light rail train during my trip": 0 = strongly disagree, 1 = disagree, 2 = agree, $3=$ strongly agree

Categorical response to the question "Do any of the following present difficulties in getting to public transit? (a) crossing busy streets, (b) lack of sidewalks, (c) distance is too far"; $0=$ no, $1=$ yes , composite variable created by equally responses for $(\mathrm{a}),(\mathrm{b})$, and (c)

Categorical response to three statements: (a) "Service on public transit is generally reliable" (b) "Public transit can generally get me where I need to go" (c) "I generally feel safe using public transit"; $0=$ strongly disagree, 1 = disagree, 2 = agree, 3 = strongly agree, composite variable created by equally weighting responses to (a), (b), and (c)

Driving expressed as dichotomous variable: $0=$ respondent did not drive a car in the last month, $1=$ respondent possesses driver's license and drove a car in the last month

Categorical response to the following: "How often do you go out in a typical week? going out mean leaving your apartment, house, or yard to go someplace else"; $0=$ rarely or never, $1=$ one or two times per week, 2 = three to five times per week, $3=$ more than five times per week

Living arrangement of respondent expressed as dichotomous variable: $0=$ live with spouse, partner, children, friend(s), relatives(s), personal or medical assistant, $1=$ live alone

Dwelling type expressed as dichotomous variable: $0=$ detached house, 1 = apartment or condominium 
Variable

(Data Source)

walkdist (survey)

\%sfhome (U.S. Census)

busstops (NFTA, VTA)

busservice (NFTA, VTA)
Operational Definition

Time in minutes to walk from respondent's home to nearest bus stop or rail station expressed as a continuous variable

Share (expressed as percentage) of dwellings classified as single-family home in respondent's home zip code

Number of bus stops for all bus routes in zip code expressed as continuous variable

Number of buses on all routes (according to current bus schedules) serving zip code during a 24-hour period on a typical weekday expressed as a continuous variable

Note: NFTA denotes Niagara Frontier Transportation Authority; VTA denotes Santa Clara Valley

Transportation Authority

The "personal characteristics and capacity" vector includes self-reported age, sex, race, and income from the survey. Also included is the respondent's reliance on a cane or wheelchair. The vector of "perceived barriers to transit access" includes variables measuring the respondent's familiarity with the transit system, the degree to which a transfer on the transit trip to another bus or route is perceived as a barrier, and two composite variables that use survey responses to describe how physical barriers and perception of transit influence the decision to ride public transit. The "access and mobility" vector measures driving and licensure, frequency of leaving home, whether the respondent lives alone or lives with others, and dwelling type. The final vector, "neighborhood characteristics," describes environmental attributes, including perceived walking distance (from the survey), and share of nearby homes that are single-family (from the U.S. Census). The number of daily bus runs (all bus routes combined) and the number of bus stops is summed for each ZIP code. The transit service supply measures (coupled with the share of nearby dwelling units that are single-family homes) serve as a proxy for urban density and improve upon previous research by not assuming that transit service frequency is homogeneous. ${ }^{13}$

Table 6 reports the statistical mean, maximum, minimum, and standard deviation for the dependent and independent variables. Note that an identical share (65 percent) of respondents in the two cities rode transit one or more times in the last year, and transit riders in San José rode with greater frequency than riders in Buffalo.

\subsection{Findings}

Table 7 presents the results of regression analysis, performed according to the plan outlined using SPSS.

The positive/negative signs of estimated regression coefficients of statistically significant independent variables are in anticipated directions, confirming hypothesized relationships between dependent and independent variables. The binary logistic models have lower $r^{2}$ values than the linear regression models. Among the linear regression models, the San José model is the most parsimonious, followed by the pooled model and, finally, the Buffalo model.

\footnotetext{
${ }^{13}$ Bus service is quantified rather than rail service because older adults ride buses a greater percentage of the time, and buses provide a mobility function throughout Buffalo's and San Josés neighborhoods that light rail does not, as light rail is oriented toward commuting to the central city.
} 
Table 6: Variable Characteristics

\begin{tabular}{|c|c|c|c|}
\hline \multirow[t]{2}{*}{ Variable } & \multicolumn{2}{|c|}{ Buffalo, NY } & San José, CA \\
\hline & mean & $\min , \max ($ st. dev $)$ & mean $\min , \max ($ st. dev $)$ \\
\hline
\end{tabular}

Dependent variables

\begin{tabular}{|c|c|c|c|c|}
\hline $\begin{array}{l}\text { transridefreq } \\
\text { transitride }\end{array}$ & $\begin{array}{r}35 \\
0.65\end{array}$ & $\begin{array}{c}0,250(74) \\
0,1(0.48)\end{array}$ & $\begin{array}{r}64 \\
0.65\end{array}$ & $\begin{array}{c}0,250(95) \\
0,1(0.48)\end{array}$ \\
\hline \multicolumn{5}{|l|}{ Independent variables } \\
\hline buffalosanjosé dummy & 0.64 & $0,1(0.48)$ & 0.64 & $0,1(0.48)$ \\
\hline \multicolumn{5}{|c|}{ Personal Characteristics and Capacity } \\
\hline age & 74 & $62,98(7)$ & 77 & $60,95(7)$ \\
\hline $\operatorname{sex}$ & 0.56 & $0,1(0.50)$ & 0.69 & $0,1(0.46)$ \\
\hline race & 0.72 & $0,1(0.45)$ & 0.27 & $0,1(0.45)$ \\
\hline income & 2.75 & $1,5(0.95)$ & 2.83 & $1,5(1.18)$ \\
\hline cane & 0.67 & $0,3(1.03)$ & 0.72 & $0,3(0.99)$ \\
\hline wheelchair & 0.1 & $0,3(0.36)$ & 0.15 & $0,3(0.40)$ \\
\hline \multicolumn{5}{|l|}{ Perceived Barriers } \\
\hline knowledge & 1.32 & $0,3(0.83)$ & 1.64 & $0,3(0.74)$ \\
\hline transfer & 1.67 & $0,3(0.80)$ & 1.85 & $0,3(0.73)$ \\
\hline physicalbarriers & 0.79 & $0,1(0.29)$ & 0.67 & $0,1(0.33)$ \\
\hline compositeperception & 2.58 & $0,1(0.46)$ & 1.95 & $0,3(0.39)$ \\
\hline \multicolumn{5}{|l|}{ Access and Mobility } \\
\hline drive & 0.64 & $0,1(0.48)$ & 0.52 & $0,1(0.40)$ \\
\hline leavehouse & 2.35 & $0,3(0.79)$ & 2.37 & $0,3(0.76)$ \\
\hline livealone & 0.26 & $0,1(0.44)$ & 0.54 & $0,1(0.50)$ \\
\hline housetype & 0.71 & $0,1(0.46)$ & 0.69 & $0,1(0.46)$ \\
\hline \multicolumn{5}{|l|}{ Neighborhood Characteristics } \\
\hline walkdist & 7.64 & $2,45(6.39)$ & 11.96 & $0,80(10.10)$ \\
\hline \%sfhome & 56.36 & $5,90(17.44)$ & 37.51 & $0,80(18.33)$ \\
\hline busstops & 123 & $69,224(44)$ & 86 & $10,184(43)$ \\
\hline busservice & 267 & $22,661(119)$ & 268 & $0,632(184)$ \\
\hline
\end{tabular}

In Model 1, a pooled linear regression for Buffalo and San José, the adjusted $r^{2}$ suggests that independent variables explain 38 percent of the variation in transit ridership frequency among respondents in Buffalo. Nine variables (including the constant) are statistically significant at the 0.90 level or greater: respondents ride transit more frequently if they have lower incomes, do not drive, are not members of the white racial group, have shorter perceived walking time to transit, are more comfortable in their knowledge of the transit system, walk with a cane, or use a wheelchair. In addition, a survey respondent's location in Buffalo or San José is statistically significant in the pooled model. Model 2, the linear regression for Buffalo, has an adjusted 
Table 7a: Model Results (Models 1-3)

\begin{tabular}{|c|c|c|c|}
\hline Variable & $\begin{array}{c}\text { Model } 1 \\
\text { Buffalo + San José }\end{array}$ & $\begin{array}{l}\text { Model } 2 \\
\text { Buffalo }\end{array}$ & $\begin{array}{l}\text { Model } 3 \\
\text { San José }\end{array}$ \\
\hline Dep. variable & transitridefreq & transitridefreq & transitridefreq \\
\hline $\begin{array}{l}\text { Independent variables } \\
\text { constant } \\
\text { buffalosanjosé dummy }\end{array}$ & $\begin{array}{l}+219.014 * * * \\
+23.984 *\end{array}$ & $+191.737 * *$ & $+289.830 * * *$ \\
\hline $\begin{array}{l}\text { Personal Characteristics and Capacity } \\
\text { age } \\
\text { sex } \\
\text { race } \\
\text { income } \\
\text { cane } \\
\text { wheelchair }\end{array}$ & $\begin{array}{l}-0.735 \\
-10.356 \\
-24.815 * * \\
-12.722 * * * \\
+7.609 * \\
-18.861 *\end{array}$ & $\begin{array}{r}-0.309 \\
2.291 \\
-20.462 \\
-10.295 \\
3.638 \\
-27.796\end{array}$ & $\begin{array}{c}-1.153 \\
-19.280 * \\
-25.619 * \\
-10.138 * \\
8.111 \\
-18.088\end{array}$ \\
\hline $\begin{array}{l}\text { Perceived Barriers } \\
\text { knowledge } \\
\text { transfer } \\
\text { physicalbarriers } \\
\text { compositeperception }\end{array}$ & $\begin{array}{c}-19.315 * * * \\
-6.576 \\
-11.039 \\
7.214\end{array}$ & $\begin{array}{r}-9.428 \\
-14.537 \\
-32.312 \\
-1.246\end{array}$ & $\begin{array}{c}-26.560 * * * \\
-3.34 \\
-11.249 \\
17.075\end{array}$ \\
\hline $\begin{array}{l}\text { Access and Mobility } \\
\text { drive } \\
\text { leavehouse } \\
\text { livealone } \\
\text { housetype }\end{array}$ & $\begin{array}{c}-79.061 * * * \\
8.659 \\
6.983 \\
-11.807\end{array}$ & $\begin{array}{c}-68.739 * * * \\
+20.844 * * \\
-1.567 \\
12.468\end{array}$ & $\begin{array}{c}-85.410 * * * \\
1.471 \\
18.319 \\
-20.119\end{array}$ \\
\hline $\begin{array}{l}\text { Neighborhood Characteristics } \\
\text { walkdist } \\
\text { \%sfhome } \\
\text { busstops } \\
\text { busservice }\end{array}$ & $\begin{array}{l}-1.062 * * \\
0.152 \\
0.048 \\
0.01\end{array}$ & $\begin{array}{c}-0.692 \\
-0.11 \\
0.088 \\
0.069\end{array}$ & $\begin{array}{c}-1.087 * \\
0.067 \\
0.098 \\
0.001\end{array}$ \\
\hline $\begin{array}{l}\text { Model Characteristics: } \\
\mathrm{n} \\
\mathrm{df} \\
r^{2} \\
\text { adj. } r^{2}\end{array}$ & $\begin{array}{l}\text { Model } 1 \\
307 \\
19 \\
0.42 * * * \\
0.38 * * *\end{array}$ & $\begin{array}{l}\text { Model } 2 \\
109 \\
18 \\
0.38 * * * \\
0.25 * * *\end{array}$ & $\begin{array}{l}\text { Model } 3 \\
198 \\
18 \\
0.46 \\
0.40 * * *\end{array}$ \\
\hline
\end{tabular}

${ }^{*} p<0.10$, significant at the 0.10 level

${ }^{* *} p<0.05$, significant at the 0.05 level

${ }^{* * *} p<0.01$, significant at the 0.01 level

$r^{2}$ value of 0.25 and produces two independent variables (besides the constant) significant at the 0.95 level or higher. Survey respondents ride transit more frequently if they are nondrivers 
Table 7b: Model Results (Models 4-6)

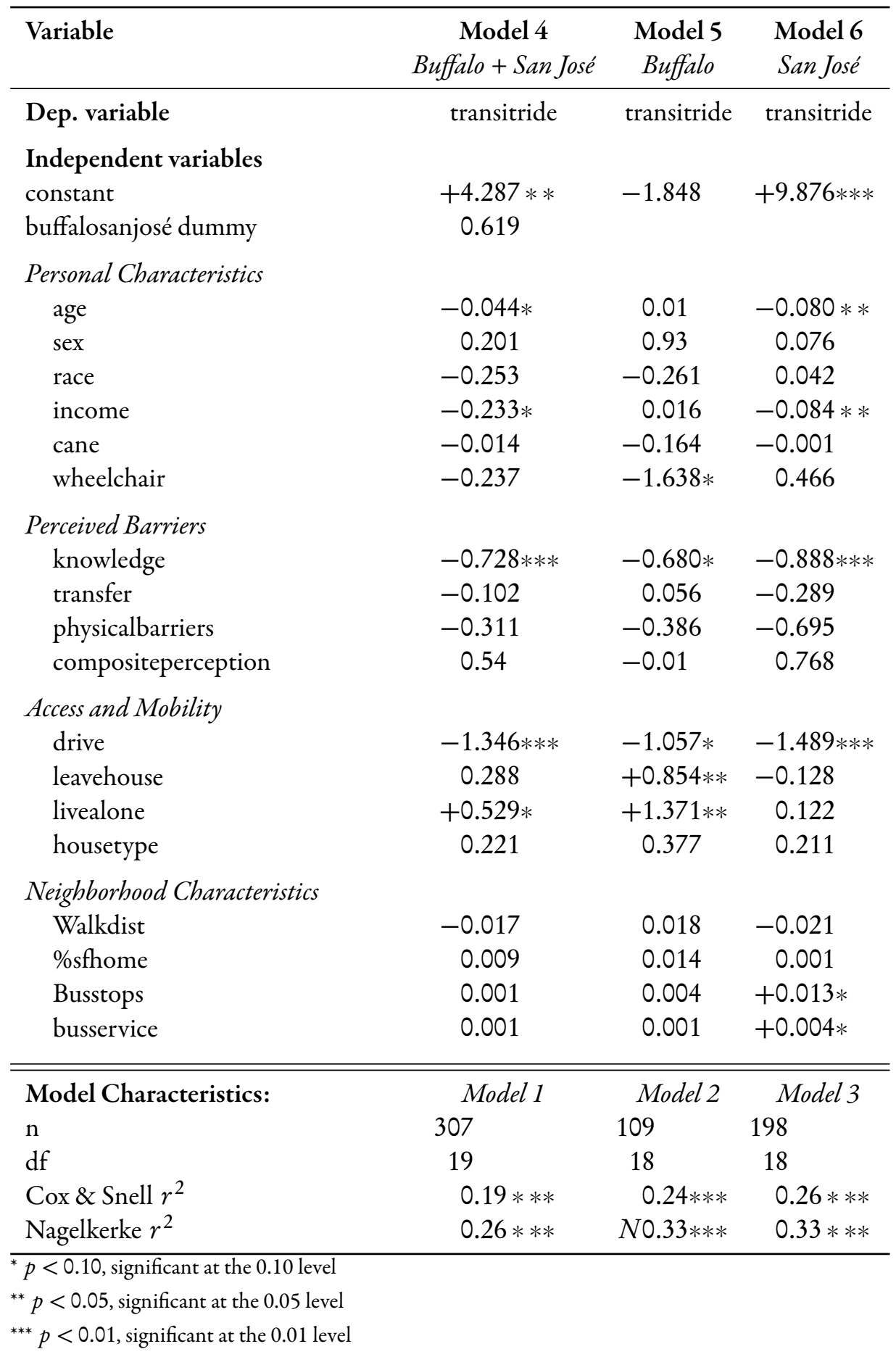

and if they leave home more frequently. Model 3, linear regression for San José, is the most parsimonious of all models, with an adjusted $r^{2}$ value of 0.40 . Survey respondents ride transit 
more frequently if they are male, have lower incomes, are nonwhite, do not drive, have shorter perceived walking time to transit, and are more comfortable in their knowledge of the transit system.

The second set of models, which employs binary logistic regression to assess the independent variables that explain whether or not a respondent has used public transit one or more times in the last year, have lower $r^{2}$ values than the linear regression models. In Model 4, a pooled analysis for Buffalo and San José, riding transit (or not riding transit) is influencedrepresented by statistically significant estimated coefficients in the regression equation-by younger age, lower income, being a nondriver, living alone, and greater knowledge of the transit system. In Model 5, the statistically significant variables that influence riding transit in Buffalo include being a nondriver, leaving home more often, living alone, greater knowledge of the transit system, and not using a wheelchair. Model 6 suggests that, in San José, seven variables (including the constant) have a statistically significant effect on riding transit: younger age, lower income, being a nondriver, greater knowledge of the transit system, and more nearby bus stops and bus service.

Each of the six variables describing personal characteristics and capacity show statistical significance in at least one of the models; age, race, and income are the most significant measures. In the models in which they are statistically significant, use of a cane increases the frequency with which a respondent uses public transit, and use of a wheelchair reduces the frequency of use. Among the perceived barriers to riding transit, a respondent's knowledge of the transit system has a positive influence on the decision to ride transit or the frequency of riding transit in five of the six models. The other independent variables in this vector-the burden of transferring and a composite variable describing physical and perceptual barriers-are not statistically significant in any of the models, but including them improves the performance of the models. Among the access and mobility variables, the drive variable is statistically significant in all models, and leavehouse and livealone are statistically significant in several of the models, but housetype is not statistically significant. Of the neighborhood variables, walking distance to transit and the supply of bus service are statistically significant only in the San José linear regression models. The share of nearby single-family homes is not statistically significant.

Of the variables of particular interest to this study, perceived walking distance to transit is statistically significant in both the pooled and San José linear models. Greater walking distance to transit reduces the frequency of riding transit. A possible rationale for the limited explanatory power of the transit proximity variable in the Buffalo models is that the urban form in Buffalo is relatively homogeneous throughout the city, with a pre-1920s regular grid street structure (Hess 2005b) and uniform transit coverage (Hess 2005a). " "Old Urbanism" features such as medium to high residential density, uniform street grid, sidewalks, and walkable commercial corridors along arterials result in relatively uniform transit accessibility throughout the city. In contrast, San José is characterized by a more varied urban structure, including neighborhoods within the municipal boundary having arguably suburban characteristics that reduce the convenience of walking to public transit.

Proximity to transit does not have a statistically significant influence in the binary logistics models, suggesting it does not have broad influence on older adults' choice to ride public transit,

\footnotetext{
${ }^{14}$ A recent study (Hess and Almeida 2007) of the effect of proximity to public transit on property values in Buffalo determined that residents place greater value on proximity to transit stops (measured by straight-line distance) than on walking distance to transit stops (measured along a street network).
} 
but it is statistically significant in the linear models, suggesting that it has an influence on the frequency of riding transit. A possible explanation is that older adults with penchants for riding transit choose household locations with greater proximity to transit.

Accessibility is a key descriptor of place within a metropolitan area. In previous research, place within a metropolitan area has been strongly associated with mode choice, and in some cases place is the dominant predictor (Rosenbloom and Waldorf 2001) of transit ridership. The survey data in Buffalo and San José, however, suggest that place has less influence on mode choice than other variables, especially personal characteristics and capacity. Nevertheless, the associations revealed by this survey data between transit ridership and perceived proximity offer a basis for additional research.

The linear models are used to predict the variation in transit ridership with walking distance in San José. This is accomplished by "solving" the linear regression equation using the variable means reported in Table 6 combined with the estimated intercept and estimated coefficients in Table 7 while varying the walking distance. The results are shown in Figure 1: women ride transit two-thirds more frequently than men; for older adults having typical characteristics for all of the explanatory variables, each additional five minutes of walking distance to a transit stop or transit station reduces the frequency of riding transit by nine percent for women and eight percent for men.

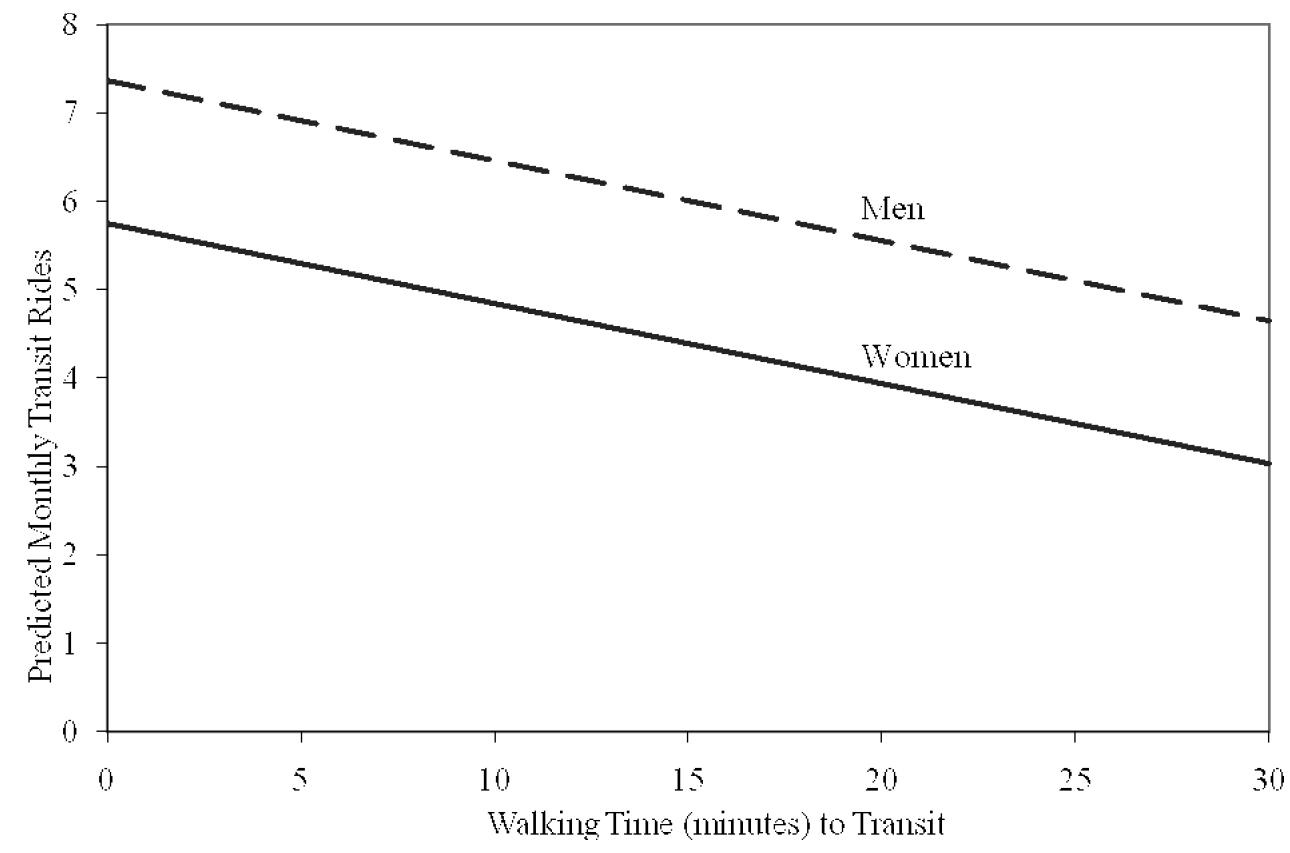

Figure 1: Regression Model Estimation: Variation in Transit Ridership Frequency and Proximity

The model predicts that a nondriving older adult having typical characteristics and living within a 10-minute walk of transit will ride transit at a rate 83 percent higher than a driving older adult. Model estimations of transit ridership frequency suggest that drivers are more sensitive to longer walking distance than nondrivers. In San José, each additional five minutes in 
perceived walking distance to transit decreases transit ridership frequency by five percent for nondrivers and by 25 percent for drivers. In San Jose, nonwhite older adults ride transit 56 percent more frequently than white older adults, and each additional $\$ 1,000$ in monthly income reduces ridership frequency by approximately 18 percent.

In Buffalo, men who leave home five times or more per week ride transit nine times as frequently as men who leave home one or two times per week, and women who leave home five times or more per week ride transit seven times as frequently as women who leave home one or two times per week. Men who do not drive ride transit nine times as frequently as men who drive, and women who do not drive ride transit eight times as frequently as women who drive.

This study fills a gap in research on proximity to transit by investigating the differential effects that perceived walking distance has on older adults' mode choice. However, the small sample size limits the power to determine relationships between certain variables. Other potential weaknesses of the research include the use of self-reported data, recall bias, and possible response bias. In addition, some older adults walk faster or with greater ease than others and these differences are masked by the data. This study does not control for self-selection among the respondents; that is, the decision to drive a vehicle and the decision to ride transit may influence housing location choice. As mentioned previously, older adults who prefer riding transit may live in neighborhoods where there is greater service and where walking distances are reduced.

In Buffalo, a consistently favorable urban structure-including "Old Urbanism" features such as mixed uses, high densities, and walkable streets with sidewalks-may limit the power of dependent variables to explain variation in the independent variable. The use of environmental variables at the ZIP code level, rather than in smaller geographic units such as Census block groups, is likely to arbitrarily mask important variations in geographic phenomena.

Future research on this topic should use smaller areal units for the inclusion of geographical phenomena. A focus on the role that proximity and walking access to transit plays on a trip-bytrip basis would be productive, as trip purposes and characteristics of a trip (weather conditions, traveling with others, carrying parcels) certainly play a role in the decision to use public transit.

Urban planners and transportation managers should be concerned with how those who use public transit view this travel mode choice and whether it accommodates their travel needs. Individual perspectives about the convenience of riding transit are more important than objective measures of transit accessibility, since individual perspectives dictate behavior. Table 8 shows that in Buffalo, 57 percent of respondents who drive agree or strongly agree with the statement "If I were no longer able to drive, it would be difficult for me to use public transit for the majority of my travel needs." In San José, 71 percent of respondents who drive agree or strongly agree with this statement. Note that San José has more new housing built at lower density than does Buffalo (see Table 1). Future research should seek to redress barriers to riding transit for older adults, especially when those barriers include (mis)perceptions that diverge from objective analysis.

The suspected barriers that older adults face do not affect transit ridership frequency as strongly as personal characteristics and capacity, whether an older adult does or does not drive, and walking distance to transit. Older adults who seldom or never ride transit may report that they are unfamiliar with the transit system because they do not ride transit. A goal of transit marketing and advertising campaigns could be to ensure that all older adults have working knowledge of the location of bus stops and routes near their homes or common destinations, so 
Table 8: Perceived Challenge of Transit Dependency

"If I were no longer able to drive, it would be difficult for me to use public transit for the majority of my travel needs."

\begin{tabular}{lrr} 
& Buffalo, NY & San José, CA \\
\hline Strongly agree & $23 \%$ & $29 \%$ \\
Agree & $34 \%$ & $42 \%$ \\
Disagree & $36 \%$ & $25 \%$ \\
Strongly disagree & $7 \%$ & $4 \%$ \\
\hline
\end{tabular}

Responses summarized for respondents with a driver's license who drove an automobile within the last month and valid responses for relevant questions. Nondrivers do not have a driver's license or have a driver's license but did not drive during the last month. (For Erie County, $\mathrm{n}=175$; for Santa Clara County, $\mathrm{n}=114$ ).

that even nonriders have enough information to help them feel comfortable making an occasional transit ride when they lack other means. This could be accomplished through information campaigns targeting older adults and through rider training and buddy programs. Nevertheless, transportation planners should be reminded that public transit captures a small share of trips for older adults, and enhancements to access and mobility for older adults should include public transit along with other modes of travel.

\section{Conclusions}

An effective and easy-to-use transit system is an important ingredient for sustainable cities and regions, and convenient access to transit stops and stations makes transit attractive to the largest possible pool of users (Levinson 1992). This includes current transit riders-the majority of whom are now transit dependent or downtown commuters (Jones 1985) — as well as new riders, including older adults.

In most North American cities, public transit is not a reasonable substitute for the private vehicle under most circumstances, and this holds true for older adults. ${ }^{15}$ While Buffalo and San José have consistent transit coverage, automobile-oriented patterns of development have created places that are difficult to serve with public transit because origins and destinations are dispersed and housing and employment are mismatched. When transit service is provided in low-density areas, infrequent bus service (due to high operating costs) can mean that service does not match the convenience of automobiles. Characteristics that can make transit more convenient for older adults-including reduced-fare programs, additional bus stops, expanded use of low-floor vehicles, ${ }^{16}$ and policies that allow drivers to deviate from regular transit routes to

${ }^{15}$ For older adults to choose public transit it must be available as an option, and about one-third of respondents to the 1995 Nationwide Personal Transportation Survey reported that public transit is not available in their town or city (Giuliano 1999). The U.S. DOT (Federal Highway Administration 2001) reports that only 45 percent of American households have access to public transportation. Access to public transportation is an even greater challenge for older adults who live in nonmetropolitan areas. Half of all adults, particularly in rural areas and small towns, do not have the option of travel by public transportation because service is not available in their area (Bailey 2004).

${ }^{16}$ For example, a survey of 225 older adult bus riders in Philadelphia reveals that 65 percent of respondents report difficulty with stepping up onto a bus and negotiating aisles while in motion (Patterson 1985). 
collect passengers closer to their homes and deliver passengers closer to their destinations-do not make a bus network operate more efficiently or with less expense. In this sense, older adults are a challenging submarket to serve, but a submarket that is nonetheless predicted to grow quickly in the coming years. The traditional neighborhoods of Buffalo and San José can, however, offer older adults - provided they maintain a minimum level of physical mobility—travel options that support autonomy.

\section{Acknowledgments}

This research was supported by the Region Two University Transportation Research Center and the Mineta Transportation Institute. ${ }^{17}$ Todd Goldman, Trixie Johnson, and Buz Paaswell supported the development of the research. Earlier versions of this research were presented at the second Access to Destinations Conference in August, 2007 at the University of Minnesota and at the Association of Collegiate Schools of Planning 48th Annual Conference in October, 2007 in Milwaukee, Wisconsin. Alex Bitterman, Beverly McLean, Steven Nagowski, and Samina Raja offered valuable comments and suggestions. Bhakti Kulkarni and Carl Sadowski provided research assistance.

\section{References}

Alsnih, R. and D. Hensher. 2003. The mobility and accessibility expectations of seniors in an aging population. Transportation Research A 37: 903-916. doi:10.1016/S0965-8564(03) 00073-9.

Bailey, L. 2004. Aging Americans: Stranded without options. Washington, D.C.: Surface Transportation Policy Project.

Banister, D. and A. Bowling. 2003. Quality of life for the elderly: The transport dimension. Transport Policy 11: 105-115. doi:10.1016/S0967-070X(03)00052-0.

Beesley, M. and J. Kain. 1964. Car ownership and public policy: An appraisal of traffic in towns. Urban Studies 1 (2): 174-203.

Booth, M., N. Owen, A. Bauman, O. Clavisi, and E. Leslie. 2000. Socio-cognitive and perceived environment influences associated with physical activity in older Australians. Preventive Medicine 31: 15-22.

Burkhardt, J. 2003. Critical measures for transit service quality in the eyes of older travelers. Transportation Research Record 1835: 84-92. doi:10.3141/1835-11.

Burkhardt, J., A. McGravock, and C. Nelson. 2002. Improving public transit options for older persons. Technical Report Transit Cooperative Research Program Report No. 82, Transportation Research Board, Washington D.C.

Cervero, R. and K. Kockelman. 1997. Travel demand and the three Ds: Density, diversity, and design. Transportation Research D 7: 265-284.

Cheslow, M. and J. Neels. 1980. Effect of urban development patterns on transportation energy use. Transportation Research Record 764: 70-78.

Collia, D., J. Sharp, and L. Giesbrecht. 2003. The 2001 National Household Travel Survey: A look into the travel patterns of older Americans. Journal of Safety Research 34: 461-470. doi:10.1016/j.jsr.2003.10.001.

\footnotetext{
${ }^{17}$ This project has not yet undergone peer review by the Mineta Transportation Institute.
} 
Corti, B., R. Donovan, and C. Holman. 1996. Factors influencing the use of physical activity facilities: Results from qualitative research. Health Promotion Journal of Australia 6 (1): 16-21. doi:10.1016/j.amepre.2005.11.007.

Coughlin, J. and A. Lacombe. 1997. Transportation and our aging population. Volpe Transportation Journal Spring: 43.

Cozens, P., R. Neale, D. Hillier, and J. Whittaker. 2004. Tackling crime and fear of crime while waiting at Britain's railway stations. Journal of Public Transportation 7 (3): 23-41.

Cunningham, G. and Y. Michael. 2004. Concepts guiding the study of the impact of the built environment on physical activity for older adults: A review of the literature. American Journal of Health Promotion 18: 435-443.

Dollemore, D. 2002. Questions arise as more older Americans outlive driving privilege. URL. Accessed June 29, 2007, URL http://www.nih.gov/news/pr/jul2002/nia-29.htm.

Evans, E. 2001. Influences on mobility among non-driving older Americans. Transportation Research Circular E-C026, American Association of Retired Persons, Washington, D.C.

Evans, J. 1999. Mobility and safety focus group research report. Technical report, Southeast Michigan Council of Governments, Detroit, MI.

Federal Highway Administration. 2001. National Household Travel Survey. Washington, D.C.: Bureau of Transportation Statistics and Federal Highway Administration.

Frank, L. and P. Engelke. 2001. The built environment and human activity patterns: Exploring the impact of urban form on public health. Journal of Planning Literature 16 (2): 202-128.

Frank, L., P. Engelke, and T. Schmid. 2003. Health and community design: The impact of the built environment on physical activity. Washington, D.C.: Island Press.

Frey, W. 2003. Boomers and seniors in the suburbs: Agingpatterns in Census 2000. Washington, D.C.: Brookings Institution.

Giuliano, G. 1999. The role of public transit in the mobility of low-income households. Technical report, Metrans Transportation Center, Los Angeles.

Glasgow, N. and R. Blakeley. 2000. Older nonmetropolitan residents' evaluations of their transportation arrangements. Journal of Applied Gerontology 19 (1): 95-116.

Golledge, R. and J. Stimson. 1997. Spatial behavior: A geographic perspective. New York: The Guilford Press.

Handy, S. 1996a. Understanding the link between urban form and nonwork travel behavior. Journal of Planning Education and Research 15: 183-198.

- - 1996b. Urban form and pedestrian choices: A study of Austin neighborhoods. Transportation Research Record 1552: 135-144.

Handy, S., M. Boarnet, R. Ewing, and R. Killingsworth. 2002. How the built environment affects physical activity: Views from urban planning. American Journal of Preventive Medicine 23: 64-73. doi:10.1016/S0749-3797(02)00475-0.

Handy, S. and K. Clifton. 2001. Local shopping as a strategy for reducing automobile travel. Transportation 28: 317-346. doi:10.1023/A:1011850618753.

Handy, S., K. Clifton, and J. Fisher. 1998. The effectiveness of land use policies as a strategy for reducing automobile dependence: A study of Austin neighborhoods. Research Report SWUTC/98/467501-1, University of Texas, Austin.

Hayden, S., K. Lupher, E. Caldwell, T. Miller, M. Kobayashi, R. Reynolds, S. Fisher, L. Tyson, H. Spano, and G. Diggs. 2004. Strengths and needs assessment of older adults in the Denver metro area. Technical report, National Research Center, Boulder. 
Hess, D. 2005a. Access to employment for adults in poverty in the Buffalo-Niagara region. Urban Studies 42 (7): 1177-1200. doi:10.1080/00420980500121384.

- - 2005b. Transportation beautiful: Did the city beautiful movement improve urban transportation? Urban Studies 32 (4): 511-545. doi:10.1177/0096144205284402.

Hess, D. and T. Almeida. 2007. Impact of proximity to light rail rapid transit on station-area property values in Buffalo, New York. Urban Studies 44 (5/6): 1041-1068. doi:10.1080/ 00420980701256005.

Hess, D., H. Iseki, B. Taylor, and A. Yoh. 2002. Increasing transit ridership: Lessons from a survey of successful transit systems in the 1990s. Journal of Public Transportation 5 (3): $33-66$.

Hess, D. and P. Ong. 2002. Traditional neighborhoods and automobile ownership. Transportation Research Record 1805: 35-44. doi:10.3141/1805-05.

Hess, P., A. Vernez-Moudon, and J. Matlick. 2004. Pedestrian safety in transit corridors. Journal of Public Transportation 7 (2): 73-93.

Hess, P., A. Vernez-Moudon, M. Snyder, and K. Stanilov. 1997. The effect of site design on pedestrian travel in mixed-use, medium-density environments. Transportation Research Record 1578: 48-55.

- -. 1999. Site design and pedestrian travel. Transportation Research Record 1674: 9-19.

Holtzclaw, J., R. Clear, H. Dittmar, D. Goldstein, and P. Haas. 2002. Location efficiency: Neighborhood and socioeconomic characteristics determine auto ownership and use-studies in Chicago, Los Angeles, and San Francisco. Transportation Planning and Technology 25: 1-27.

Hsiao, S., J. Lu, J. Sterling, and M. Weatherford. 1997. Use of geographic information system for analysis of transit pedestrian access. Transportation Research Record 1604: 50-59. doi: 10.3141/1604-07.

Humpel, N., N. Owen, and E. Leslie. 2002. Environmental factors associated with adults' participation in physical activity: A review. American Journal of Preventive Medicine 22: 188-199. doi:10.1016/S0749-3797(01)00426-3.

Iwarsson, S. and A. Ståhl. 1999. Traffic engineering and occupational therapy: A collaborative approach for future directions. Scandinavian Journal of Occupational Therapy 6 (1): 21-28.

Jones, D. 1985. Urban transit policy: An economic and political history. Englewood Cliffs, NJ: Prentice-Hall.

Ketron, Division of the Bionetics Corporation. 1999. Baltimore region elderly activity patterns and travel characteristics study. Technical report, Baltimore Metropolitan Council, Baltimore.

King, W., J. Brach, S. Belle, R. Killingsworth, M. Fenton, and A. Kriska. 2003. The relationship between convenience and destinations and walking levels in older women. American Journal of Health Promotion 18 (1): 74-82.

Kitamura, R., T. Akiyama, T. Yamamot, and T. Golub. 2001. Accessibility in a metropolis: Toward a better understanding of land use and travel. Transportation Research Record 1780: 64-75. doi:10.3141/1780-08.

Kitamura, R., P. Mokhtarian, and L. Laidet. 1997. A micro-analysis of land use and travel in five neighborhoods in the San Francisco Bay area. Transportation 24: 125-158. doi: 10.1023/A:1017959825565. 
Levinson, H. 1992. Urban mass transit systems. In J. Edwards, ed., Transportation planning handbook, 123-174. Englewood Cliffs, NJ: Prentice-Hall.

Lloyd, R. 1997. Spatial cognition: Geographic environments. Norwell, MA: Kluwer.

Loukopoulos, P. and T. Gärling. 2005. Are car users too lazy to walk? the relation of distance thresholds for driving to the perceived effort of walking. Transportation Research Record 1926: 206-211. doi:10.3141/1926-24.

Lusk, A. 2002. Guidelines for greenways: Determining the distance to, frequency of, and human needs met by destinations on multi-use corridors. Ph.D. thesis, University of Michigan, Taubman College of Architecture and Urban Planning.

Millar, W. Expanding mobility options for older adults: Community design incentives. Cambridge, MA: White House conference on aging: Transportation solutions for an aging society, April, 2005.

Neilson, G. and W. Fowler. 1972. Relation between transit ridership and walking distances in a low-density Florida retirement area. Highway Research Record 403: 26-34.

Nelson, N. 2002. San Francisco Bay Area Older Adults Transportation Study. Technical report, Metropolitan Transportation Commission, San Francisco.

O'Gara, M. 2002. Transportation solutions in a community context: The need for better transportation systems for everyone. Testimony before the U.S. House of Representatives Highways and Transit Subcommittee of the Committee on Transportation and Infrastructure. Retrieved June 29, 2007, URL http://www.house.gov/transportation/highway/07-25-02/ ogara.html.

Ory, M., M. Kinney Hoffman, M. Hawkins, B. Sanner, and R. Mockenhaupt. 2003. Challenging aging stereotypes: Strategies for creating a more active society. American Journal of Preventive Medicine 25: 164-171. doi:10.1016/S0749-3797(03)00181-8.

Owen, N., N. Humpel, E. Leslie, A. Bauman, and J. Sallis. 2004. Understanding environmental influences on walking: Review and research agenda. American Journal of Preventive Medicine 27: 67-76. doi:10.1016/j.amepre.2004.03.006.

Parsons Brinckerhoff Quade and Douglas. 1993. The pedestrian environment. Technical report, 1,000 Friends of Oregon, Portland.

Patterson, A. 1985. Fear of crime and other barriers to use of public transportation by the elderly. Journal of Architectural and Planning Research 2: 277-288.

Patterson, P. and N. Chapman. 2004. Urban form and older residents' service use, walking, driving, quality of life, and neighborhood satisfaction. American Journal of Health Promotion 19: 45-52.

Peck, M. 2009. Barriers to fixed-route public transit for older adults. Technical report, Mineta Transportation Institute, San José.

Peel, N., J. Westmoreland, and M. Steinberg. 2002. Transport safety for older people: A study of their experiences, perceptions, and management needs. Injury Control and Safety Promotion 9(1): 19-24.

Rodriguez, D. and J. Joonwon. 2003. The relationship between non-motorized travel behavior and the local physical environment. Transportation Research D 9 (2): 171-173. doi:10. 1016/j.trd.2003.11.001.

Rosenbloom, S. 2003. The mobility needs of older Americans: Implications for transportation reauthorization. Technical report, The Brookings Institution, Washington, D.C. 
Rosenbloom, S. and G. Fielding. 1998. Transit markets of the future: The challenge of change. Transit cooperative research report 28, National Research Council, Washington, D.C.

Rosenbloom, S. and J. Morris. 1998. Travel patterns of older australians in an international context. Transportation Research Record 1617: 189-193 189-193.

Rosenbloom, S. and B. Waldorf. 2001. Older travelers: Does place or race make a difference? In Personal travel: The long and short of it, number E-C026 in Transportation Research ECircular, 103-117. Washington, D.C.

Rowe, J. and R. Kahn. 1998. Successful Aging. New York: Pantheon.

Saelens, B., J. Sallis, and L. Frank. 2003. Environmental correlates of walking and cycling: Findings from the transportation, urban design, and planning literatures. Annals of Behavioral Medicine 25 (2): 80-91. doi:10.1207/S15324796ABM2502_03.

Schimek, P. 1996. Household motor vehicle owner and use: How much does residential density matter? Transportation Research Record 1552: 120-125.

Singh, M. 2002. Exercise comes of age: Rationale and recommendations for a geriatric exercise prescription. Journals of Gerontology: Medical Sciences 57 (A): 262-282.

Southworth, M. and E. Ben-Joseph. 2003. Streets and the shaping of towns and cities. Washington, D.C.: Island Press.

Straight, A. 1997. Community transportation survey. Technical report, American Association of Retired Persons, Washington, D.C.

Tan, S. 2006. The senior class: The number of $65+$ citizens is expected to double in the next 25 years. The Buffalo News March 12, 2006.

Taylor, B., M. Garrett, and H. Iseki. 2000. Measuring cost variability in the provision of transit service. Transportation Research Record 1735: 101-112. doi:10.3141/1735-13.

Transportation Research Record and Institute of Medicine. 2005. Does the built environment influence physical activity: Examining the evidence. Special report 282, National Academy of Science, Washington D.C.

Untermann, R. 1984. Accommodating the pedestrian: Adapting towns and neighborhoods for walking and bicycling. New York: Van Nostrand Reinhold Company.

U.S. Bureau of Census. 1996. Currentpopulation reports, specialstudies, 65+ in the United States. Washington, D.C.: U.S. Government Printing Office.

- - 2000. Decennial census of population and housing. Summary files 1, 2, and 3. Washington, D.C.: U.S. Bureau of Census.

Wallace, R. and D. Franc. 1999. Literature review of the status of research on the transportation and mobility needs of older women. Technical report, National Highway Traffic Safety Administration, Washington, D.C.

Walter, C., R. Althouse, H. Humbel, M. Leys, and V. Odom. 2004. West Virginia survey of visual health: Low vision and barriers to access. Visual Impairment Research 6 (1): 53-71.

Wilcox, S., M. Bopp, L. Oberrecht, S. Kammermann, and C. McElmurray. 2003. Psychosocial and perceived environmental correlates of physical activity in rural and older African American and white women. The Journals of Gerontology B 58: 329-337.

Zhao, F., L. Chow, M. Li, I. Ubaka, and A. Gan. 2003. Forecasting transit walk accessibility: Regression model alternative to buffer. Transportation Research Record 1835: 34-41. doi: 10.3141/1835-05. 